CENDEKIA, Vol. 12, No. 1, April 2018

p ISSN: 1978 2098; e ISSN: 2407 8557

Http://cendekia.pusatbahasa.or.id; Email: cendekiaoslo@gmail.com

Center of Language and Culture Studies, Surakarta, Indonesia

Herlambang, Erik \& Fuadi. 2018. Pengaruh Budaya Organisasi dan Komunikasi

Interpersonal terhadap Kinerja Guru SMK Swasta di Kota Serang

dengan Variabel Mediasi Komitmen Organisasi.

Cendekia, (2018), 12(1): 33 50. DOI: 10.30957/cendekia.v12i.435.

\title{
PENGARUH BUDAYA ORGANISASI DAN KOMUNIKASI \\ INTERPERSONAL TERHADAP KINERJA GURU SMK SWASTA DI KOTA \\ SERANG DENGAN VARIABEL MEDIASI KOMITMEN ORGANISASI
}

\author{
Erik Herlambang \& Fuadi \\ STIE Banten \\ Jl. Letnan Jidun No. 5 C Kepandean, Serang Banten 4115 \\ Email: fuadiali71@gmail.com HP: 085946106527
}

\begin{abstract}
This study examines the influence of: 1) organizational culture on the organizational commitment of private Vocational high School (SMK) teachers in Serang; 2) interpersonal communication on the commitment of the organization of private SMK teachers in Serang; 3) organizational culture and interpersonal communication on the organization's commitment of private SMK teachers in Serang; 4) organizational culture on the performance of private SMK teachers in Serang; 5) interpersonal communication on the performance of private SMK teachers in Serang; 6) organizational commitment to the performance of private SMK teachers in Serang; and 7) the influence of organizational culture, interpersonal communication, and organizational commitment to the performance of private SMK teachers in Serang. The study used a survey research with 92 sample research. Data were taken by using questionnaire and analyzed using structure equation model (SEM). The results are as follows. First, organizational culture and interpersonal communication individually and together positively and significantly influence the teacher's commitment to private SMK organization in Serang. Second, organizational culture, interpersonal communication, and organizational commitment have positive and significant influence both individually and collectively on the performance of private SMK teachers in Serang.
\end{abstract}

Keywords: work culture, interpersonal communication, commitment, performance

\section{PENDAHULUAN}

Perkembangan ilmu pengetahuan dan teknologi telah membawa perubahan di hampir semua aspek kehidupan manusia dan berbagai permasalahan hanya dapat dipecahkan dengan upaya penguasaan dan peningkatan ilmu pengetahuan dan teknologi. Hal tersebut tidak terlepas dan keberadaan sekolah dalam menyiapkan sumber daya manusia yang kompeten dalam menghadapi tantangan zaman dan kemajuan teknologi.

Kemajuan dan perkembangan yang terjadi menghendaki setiap individu mampu bertahan hidup dan bersaing dalam kemajuan tersebut Pendidikan merupakan upaya pengembangan kemampuan dan kepribadian yang mampu menjawab tantangan 
CENDEKIA, Vol. 12, No. 1, April 2018

p ISSN: 1978 2098; e ISSN: 2407 8557

Http://cendekia.pusatbahasa.or.id; Email: cendekiaoslo@gmail.com

Center of Language and Culture Studies, Surakarta, Indonesia

Herlambang, Erik \& Fuadi. 2018. Pengaruh Budaya Organisasi dan Komunikasi

Interpersonal terhadap Kinerja Guru SMK Swasta di Kota Serang

dengan Variabel Mediasi Komitmen Organisasi.

Cendekia, (2018), 12(1): 33 50. DOI: 10.30957/cendekia.v12i.435.

sesuai dengan tuntutan dan perkembangan yang sedang dan akan terjadi. Sagala, (2007: 71) menyebutkan bahwa tugas utama sekolah adalah menjalankan proses belajarmengajar, evaluasi kemajuan peserta didik, dan meluluskan peserta didik yang berkualitas memenuhi standar yang dipersyaratkan.

Pendidikan merupakan proses pencernaan dan internalisasi nilai-nilai. Proses tersebut dapat terwujud apabila diikuti dengan kehadiran guru yang menjadi teladan dan tokoh panutan. Guru diharapkan menjadi sosok utama dalam pembelajaran dan melalui proses belajar mengajar tersebut berbagai ilmu pengetahuan, nilai, keterampilan, dan informasi yang dapat digunakan untuk mengubah diri dan kehidupan siswa. Guru tidak hadir begitu saja dalam kelas tanpa persiapan dan tanpa kemampuan, tetapi hadir dengan berbagai persiapan dan berbagai kemampuan yang memadai, serta selalu berusaha menjadikan anak didiknya menjadi manusia yang mampu hidup dengan lingkungannya di masa yang akan datang.

Menurut Robbins (1996) beberapa fungsi budaya bagi suatu organisasi yaitu 1) budaya berperan sebagai tapal batas organisasi, artinya budaya berfungsi menciptakan identitas atau ciri suatu organisasi yang dapat membedakannya dengan organisasi lain, 2) budaya dapat membawa suatu rasa identitas bagi para anggotanya, artinya budaya mampu menanamkan rasa bangga menjadi anggota organisasinya, 3) budaya dapat menumbuhkan komitmen dan kesetiaan anggota yang lebih luas terhadap organisasinya dibanding komitmen terhadap hal-hal yang lebih sempit secara individual, 4) budaya dapat meningkatkan kemantapan sistem sosial, artinya budaya organisasi dapat menimbulkan rasa kebersamaan diantara sesama anggota yang dapat mempersatukan semua komponen organisasi, dan 5) budaya berfungsi sebagai mekanisme pembuat makna dan kendali yang dapat membentuk sikap dan perilaku para anggotanya.

Kuat lemahnya budaya suatu organisasi atau perusahaan sangat tergantung pada bagaimana para karyawan menghayati dan mengamalkan nilai-nilai yang terkandung dalam budaya tersebut. Budaya yang kuat tentunya akan dapat menciptakan dan memperkuat komitmen karyawan terhadap organisasi. Dengan demikian karyawan akan tetap setia pada organisasinya dan tidak akan mudah terpengaruh oleh faktorfaktor lain, baik dari luar organisasi maupun dari dalam organisasi sendiri. Budaya perusahaan juga akhirnya akan berfungsi sebagai motivator bagi karyawan dalam melaksanakan pekerjaannya. Budaya yang kurang baik atau negatif tentunya juga akan berpengaruh pula terhadap motivasi kerja karyawan. Karyawan akan malas bekerja karena tidak ada nilai-nilai positif yang dapat mendorong agar mereka bekerja lebih baik.

Setiap karyawan dalam organisasi harus memiliki komitmen yang tinggi terhadap pencapaian misi, visi, dan tujuan organisasi. Dalam organisasi, ikatan batin antara karyawan untuk bekerja di instansi pemerintah bukan sekedar gaji, namun lebih pada ikatan batin misalnya ingin menjadi abdi negara dan abdi masyarakat, status sosial, dan sebagainya. Sehingga bila setiap karyawan memiliki komitmen yang kuat untuk 
CENDEKIA, Vol. 12, No. 1, April 2018

p ISSN: 1978 2098; e ISSN: 2407 8557

Http://cendekia.pusatbahasa.or.id; Email: cendekiaoslo@gmail.com

Center of Language and Culture Studies, Surakarta, Indonesia

Herlambang, Erik \& Fuadi. 2018. Pengaruh Budaya Organisasi dan Komunikasi

Interpersonal terhadap Kinerja Guru SMK Swasta di Kota Serang

dengan Variabel Mediasi Komitmen Organisasi.

Cendekia, (2018), 12(1): 33 50. DOI: 10.30957/cendekia.v12i.435.

memberikan prestasi terbaik bagi negara dan pelayanan terbaik pada masyarakat, maka tentunya kinerja sektor publik akan meningkat.

Beberapa faktor yang mempengaruhi proses belajar mengajar antara lain komunikasi ,budaya organisasi , komitmen guru,profesionalitas, motivasi , lingkungan kerja . Proses belajar mengejar guru bukan hanya ditentukan oleh kepala sekolah sebagai pemimpinnya, melainkan ditentukan pula oleh jenis pekerjaannya, dan teknologi yang digunakan dalam kegiatan belajar mengajar.

Sebagaimana halnya dengan proses pendidikan pada umumnya, proses belajar mengajar merupakan sejumlah komponen atau unsur yang saling berhubungan sama dengan yang lainnya seperti menciptakan situasi belajar yang kondusif dengan mengarahkan sumber kekuatan , sarana dan prasarana, serta strategi dalam pelaksanaan proses belajar mengajar yang tepat.

Sekolah sebagai lembaga yang di dalamnya terdapat siswa, guru dan staf administrasi lainnya, kepala sekolah mempunyai tanggung jawab yang cukup berat untuk mengemban tugas. Penelitian pendahuluan menggambarkan kondisi dimana guru yang mengajar di SMA Kabupaten Labuhan Batu Utara masih ada yang berada di luar kelas walaupun jam mengajar sudah dimulai.; mengajar apabila ada pengawasan dan kepala sekolah, masih ada guru komputer yang hanya mengajar teoritis saja, guru tidak membimbing siswa, masih ada guru yang masih berbincang sesama guru lainnya di luar kelas pada jam mengajar, masih ada guru yang tidak hadir mengajar ke kelas tanpa ada surat pemberitahuan, masih ada guru yang tidak membuat satuan pengajaran, rencana pengajaran dan catatan kelas atau baru menyusun satuan pelajaran dan rencana pelajaran apabila hendak naik pangkat/golongan saja, masih ada guru yang memberikan tugas kepada siswa namun tidak dikoreksi , masih ada guru yang hadir di sekolah hanya jika ada jam mengajar saja, setelah selesai mengajar langsung pulang. dan juga masih banyak guru yang kurang memanfaatkan lingkungan sekolah misalnya perpustakaan sebagai sumber belajar.

Perspektif baru dalam pendidikan, guru tidak lagi menjadi pusat kegiatan yang menentukan setiap aktivitas siswa, tetapi siswa yang menjadi pusat perhatian, siswa bebas berpikir dan bertindak (Hicks, 1970:364)., hal ini menunjukkan suatu pergeseran yang berarti terhadap guru dalam melaksanakan tugas mengajarnya. Dengan demikian bahwa mengajar merupakan aktivitas seorang guru dalam kelas untuk mengajak siswa belajar dalam suasana yang kondusif.

Pendapat yang demikian sangat cocok apabila dikaitkan dengan perkembangan atau kemajuan informasi, teknologi dan ilmu pengetahuan seperti sekarang ini. Laju ilmu pengetahuan dan teknologi yang begitu pesat tidak mungkin lagi menempatkan guru sebagai sumber belajar dan sumber pengetahuan. Hal ini bergeser karena guru adalah manusia biasa yang sering kali ketinggalan dari perkembangan itu sendiri.

Komunikasi, budaya organisasi serta komitmen guru SMA Kabupaten Labuhan Batu Utara yang kondusif dimungkinkan akan mampu mempengaruhi proses belajar mengajar guru agar dapat mengajar secara efektif, mengarahkan dan mendayagunakan 
CENDEKIA, Vol. 12, No. 1, April 2018

p ISSN: 1978 2098; e ISSN: 2407 8557

Http://cendekia.pusatbahasa.or.id; Email: cendekiaoslo@gmail.com

Center of Language and Culture Studies, Surakarta, Indonesia

Herlambang, Erik \& Fuadi. 2018. Pengaruh Budaya Organisasi dan Komunikasi

Interpersonal terhadap Kinerja Guru SMK Swasta di Kota Serang

dengan Variabel Mediasi Komitmen Organisasi.

Cendekia, (2018), 12(1): 33 50. DOI: 10.30957/cendekia.v12i.435.

komponen-komponen belajar mengajar secara optimal dan pada gilirannya dapat menghasilkan lulusan yang bermutu.

\section{TINJAUAN PUSTAKA}

Budaya Organisasi merupakan bagian dari Manajemen Sumber Daya Manusia dan Teori Organisasi. Budaya organisasi dilihat diri aspek prilaku, sedangkan Teori organisasi dilihat dari aspek sekelompok individu yang bekerja sama untk mencapai tujuan, atau organisasi sebagai wadah tempat individu bekerjasama secara rasional dan sistematis untuk mencapai tujuan. Budaya organisasional adalah sistem makna, nilainilai dan kepercayaan yang di anut bersama dalam suatu organisasi yang menjadi rujukan untuk bertindak dan membedakan organisasi satu dengan organisasi lain (Lumbanraya, 2009). Suatu budaya yang kuat merupakan perangkat yang sangat bermanfaat untuk mengarahkan perilaku, karena membantu karyawan untuk melakukan pekerjaan yang lebih baik sehingga setiap karyawan pada awal karirnya perlu memahami budaya dan bagaimana budaya tersebut di implementasikan. Lebih lanjut di katakan bahwa di dalam pertumbuhan perusahaan dan produk knowledge-based yang memuaskan, pengendalian dan pemahaman budaya perusahaan suatu organisasi merupakan kunci tanggung jawab pimpinan, seperti halnya sebagai suatu alat yang vital bagi manajemen jika ingin mencapai kinerja yang tinggi dan menjaga nilai pemegang saham.

Budaya organisasi, berdasarkan definisi tersebut di atas, dapat ditempatkan pada arah nilai (values) maupun norma perilaku (behavioral norms). Budaya organisasi sebagai nilai merujuk pada segala sesuatu dalam organisasi yang dipandang sengat bernilai (highly valued), sedangkan sebagai norma perilaku (behavioral norms) budaya organisasi mengacu pada bagaimana sebaiknya elemen-elemen (anggota) organisasi berperilaku

Komunikasi interpersonal adalah komunikasi yang dilakukan kepada pihak lain untuk mendapatkan umpan balik, baik secara langsung (face to face) maupun dengan media. Berdasarkan definisi ini maka terdapat kelompok maya atau faktual (Devito, 1997). Contoh dunia maya, misalnya komunikasi melalui internet (chatting, face book, email, dan sebagainya.). Berkembangnya dunia maya ini karena perkembangan teknologi media komunikasi

Komunikasi interpersonal adalah komunikasi yang dilakukan antara seseorang dengan orang lain dalam sebuah organisasi dimana komunikasi interpersonal ini dapat dilakukan antar individu dalam satu bagian, antar bagian dalam organisasi, antar bawahan, antar pimpinan maupun pimpinan dengan bawahan. Terdapat dua bentuk komunikasi yang biasa dilakukan dalam komunikasi interpersonal yaitu komunikasi lisan dan komunikasi tulisan (Devito, 1997)..

Keberhasilan pengelolaan organisasi sangatlah ditentukan oleh keberhasilan dalam mengelola sumber daya manusia. Seberapa jauh komitmen karyawan terhadap organisasi tempat mereka bekerja, sangatlah menentukan organisasi itu dalam mencapai 
CENDEKIA, Vol. 12, No. 1, April 2018

p ISSN: 1978 2098; e ISSN: 2407 8557

Http://cendekia.pusatbahasa.or.id; Email: cendekiaoslo@gmail.com

Center of Language and Culture Studies, Surakarta, Indonesia

Herlambang, Erik \& Fuadi. 2018. Pengaruh Budaya Organisasi dan Komunikasi

Interpersonal terhadap Kinerja Guru SMK Swasta di Kota Serang

dengan Variabel Mediasi Komitmen Organisasi.

Cendekia, (2018), 12(1): 33 50. DOI: 10.30957/cendekia.v12i.435.

tujuannya. Dalam dunia kerja komitmen karyawan terhadap organisasi sangatlah penting, karena jika para tenaga kerja berkomitmen pada organisasi, mereka mungkin akan lebih produktif, sehingga sampai-sampai beberapa organisasi berani memasukkan unsur komitmen sebagai salah satu syarat untuk memegang jabatan/posisi yang ditawarkan dalam iklan lowongan pekerjaan.

Menurut Mathis dan Jackson (2001) menyatakan bahwa komitmen organisasi merupakan tingkat kepercayaan dan penerimaan tenaga kerja terhadap tujuan organisasi dan mempunyai keinginan untuk tetap ada di dalam organisasi tersebut. Komitmen organisasi sebagai rasa identifikasi, keterlibatan, dan loyalitas yang dinyatakan oleh seorang karyawan terhadap organisasinya. Komitmen karyawan merupakan suatu hubungan antara individu karyawan dengan organisasi kerja, dimana karyawan mempunyai keyakinan dan kepercayaan terhadap nilai-nilai dan tujuan organisasi kerja, adanya kerelaan untuk menggunakan usahanya secara sungguh-sungguh demi kepentingan organisasi kerja serta mempunyai keinginan yang kuat untuk tetap menjadi bagian dari organisasi kerja. Dalam hal ini individu mengidentifikasikan dirinya pada suatu organisasi tertentu tempat individu bekerja dan berharap untuk menjadi anggota organisasi kerja guna turut merealisasikan tujuan-tujuan organisasi kerja.

Istilah Kinerja berasal dari kata job performance atau actual performance (prestasi kerja atau prestasi sesungguhnya yang dicapai oleh seseorang). Menurut Mangkunegara "kinerja adalah hasil kerja secara kualitas dan kuantitas yang dicapai oleh seorang pegawai dalam melaksanakan tugasnya sesuai dengan tanggung jawab yang diberikan kepadanya". Kinerja merupakan terjemahan dari bahasa Inggris work performance atau job performance. Kinerja dalam bahasa Indonesia disebut juga prestasi kerja. Kinerja atau prestasi kerja diartikan sebagai ungkapan kemampuan yang didasari oleh pengetahuan, sikap, keterampilan dan motivasi dalam menghasilkan sesuatu. Masalah kinerja selalu mendapat perhatian dalam manajemen karena sangat berkaitan dengan produktivitas lembaga atau organisasi.

Menurut Keith Davis faktor yang dapat mempengaruhi pencapaian kinerja adalah faktor kemampuan (abality) dan faktor motivasi (motivation) atau dengan kata lain, "performance $=$ abality + motivation". Seperti diketahui banyak orang yang mampu bekerja tetapi tidak mempunyai motivasi untuk melaksanakan sesuatu maka tidak menghasilkan kinerja, demikian juga bayak orang yang termotivasi tetapi tidak mampu melaksanakan suatu pekerjaaan, maka juga tidak menghasilkan kinerja apa-apa. Menurut Rivai (2005), disebutkan bahwa kinerja adalah hasil atau tingkat keberhasilan seseorang secara keseluruhan selama periode tertentu di dalam melaksanakan tugas dibandingkan dengan berbagai kemungkinan, seperti standar hasil kerja, target atau sasaran atau kriteria yang telah ditentukan terlebih dahulu dan telah disepakati bersama.

\section{METODE}

Dilihat dari tujuannya, penelitian termasuk penelitian deskriptif dan verifikatif. Metode yang digunakan adalah metode deskriptif survey dan explanatory survey. Tipe 
CENDEKIA, Vol. 12, No. 1, April 2018

p ISSN: 1978 2098; e ISSN: 2407 8557

Http://cendekia.pusatbahasa.or.id; Email: cendekiaoslo@gmail.com

Center of Language and Culture Studies, Surakarta, Indonesia

Herlambang, Erik \& Fuadi. 2018. Pengaruh Budaya Organisasi dan Komunikasi

Interpersonal terhadap Kinerja Guru SMK Swasta di Kota Serang

dengan Variabel Mediasi Komitmen Organisasi.

Cendekia, (2018), 12(1): 33 50. DOI: 10.30957/cendekia.v12i.435.

penelitian ini juga dapat dimasukkan ke dalam kategori penelitian kausalitas. Unit analisis dalam penelitian ini adalah individu, yaitu semua guru SMK Swasta di Kota Serang yang menjadi sampel penelitian. Time horizon dalam penelitian ini adalah cross sectional yaitu informasi dari populasi dikumpulkan langsung dari lokasi secara empiris, dengan tujuan untuk mengetahui pendapat dari populasi terhadap obyek yang sedang diteliti, melalui instrumen yang disebarkan oleh peneliti kepada sampel sasaran.

Penelitian ini dilaksanakan di SMK Swasta Kota Serang Provinsi Banten. Jangka waktu penelitian ini adalah cross sectional April sampai dengan Desember 2017. Populasi dalam penelitian ini adalah seluruh guru SMK Swasta di Kota Banten yang berjumlah 460 orang. Jumlah sampel yang diambil sebanyak $20 \%$ yaitu sebanyak 92 orang. Data diperoleh dengan menggunakan teknik utama yaitu teknik kuesioner. Teknik kuesioner dilakukan dengan memberikan pertanyaan tertulis pada responden. Jenis pertanyaan yang digunakan dalam kuesioner dengan pertanyaan tertutup.

Butir pertanyaan disusun berdasarkan indikator. Alternatif jawaban disusun dengan menggunakan sekala Likert, yaitu dengan memberikan lima (5) alternative jawaban pada responden mulai sangat setuju, setuju, ragu-ragu, tidak setuju, sangat tidak setuju.

Untuk menganalisis pengaruh baik secara parsial maupun secara simultan dilakukan dalam tiga tahapan analisis yaitu analisis univariate, bivariate, dan multivariate.

1. Pengembangan Model Berbasis Teori

Pada prinsipnya SEM berbasis pada hubungan kausalitas di mana perubahan sebuah variabel diasumsikan menghasilkan perubahan pada variabel yang lain. Ada empat kriteria kesepakatan dalam membangun hubungan kausal yaitu: 1) asosiasi yang cukup antara dua variabel, 2) anteseden temporal dari penyebab dan akibat, 3) kelangkaan variabel kausal alternatif, dan 4) basis teori untuk hubungan tersebut.

2. Menyusun diagram jalur

Penelitian ini mengandung 2 konstruk eksogen serta dua konstruk endogen.

3. Mengubah Diagram Jalur Menjadi Persamaan Struktural

Pada tahap ini dibentuk model persamaan yang lebih formal melalui serangkaian persamaan yang mendefinisikan: 1) persamaan struktural yang mencerminkan hubungan antar konstruk (structural equation model), 2) model pengukuran yang menspesifikasi variabel indikator yang membentuk konstruk (measurement model) dan 3) serangkaian matrik yang mengindikasikan setiap korelasi hipotetik antarkonstruk.

\section{HASIL}

Berkaitan dengan tingkat pendidikan guru, berdasarkan data yang telah terkumpul, dapat dijelaskan bahwa jumlah guru yang hanya berpendidikan D3 sebanyak 10 orang $(11 \%)$, berpendidikan S1 sebanyak 74 orang $(80 \%)$, berpendidikan S2 sebanyak 8 orang $(9 \%)$, dan berpendidikan S3 sebanyak 0 orang $(0 \%)$. 
CENDEKIA, Vol. 12, No. 1, April 2018

p ISSN: 1978 2098; e ISSN: 2407 8557

Http://cendekia.pusatbahasa.or.id; Email: cendekiaoslo@gmail.com

Center of Language and Culture Studies, Surakarta, Indonesia

Herlambang, Erik \& Fuadi. 2018. Pengaruh Budaya Organisasi dan Komunikasi

Interpersonal terhadap Kinerja Guru SMK Swasta di Kota Serang

dengan Variabel Mediasi Komitmen Organisasi.

Cendekia, (2018), 12(1): 33 50. DOI: 10.30957/cendekia.v12i.435.

Jumlah guru yang menjadi sampel penelitian, mereka yang bekerja selama 1-10 tahun sebanyak 34 orang (37\%), antara 11-20 tahun sebanyak 31 orang (34\%), antara 21-30 tahun sebanyak 25 orang (27\%), dan lebih daari 30 tahun sebanyak 2 orang (2\%).

Hasil jawaban responden pada 8 item pertanyaan budaya organisasi menunjukkan skor rata-rata sebesar 24,27 dengan rata-rata standar deviasi sebesar 2,15. Skor maksimal yaitu 29 dan skor terkecil yaitu 21. Range atau jarak antara skor terbesar dan skor terkecil yaitu sebesar 8. Distribusi variabel budaya organisasi berdistribusi sangat bagus karena tidak terlalu juling positif dengan skewness 0,226 masih berada di dalam ambang batas $-0,5$ sampai dengan 0,5 .

Hasil analisis deskriptif terhadap variabel Komunikasi interpersonal sebagaimana ditampilkan di atas dapat diketahui bahwa rata-rata Komunikasi interpersonal yaitu sebesar 28,9 dengan skor maksimal 36. Skor terkecil yaitu 25 dan skor terbesar yaitu 35. Range atau jarak antara skor terbesar dan skor terkecil yaitu sebesar 10. Distribusi variabel Komunikasi interpersonal berdistribusi sangat bagus karena tidak terlalu juling positif dengan skewness 0,266 masih berada di dalam ambang batas $-0,5$ sampai dengan 0,5 .

Hasil analisis deskriptif terhadap variabel komitmen organisasi sebagaimana ditampilkan di atas dapat diketahui bahwa rata-rata komitmen organisasi yaitu sebesar 32,5 dengan skor maksimal 40. Skor terkecil yaitu 28 dan skor terbesar yaitu 36. Range atau jarak antara skor terbesar dan skor terkecil yaitu sebesar 8. Distribusi variabel komitmen organisasi berdistribusi sangat bagus karena tidak terlalu juling negatif dengan skewness -0,332 masih berada di dalam ambang batas -0,5 sampai dengan 0,5.

Hasil analisis deskriptif sebagaimana ditampilkan di atas dapat diketahui bahwa rata-rata kinerja guru yaitu sebesar 37,5 dengan skor maksimal 40. Skor terkecil yaitu 34 dan skor terbesar yaitu 38. Range atau jarak antara skor terbesar dan skor terkecil yaitu sebesar 14. Distribusi variabel kinerja guru berdistribusi kurang bagus karena terlalu juling positif dengan skewness 1,4 di luar ambang batas -0,5 sampai dengan 0,5.

\section{Analisis Struktural Equational Modeling}

Penelitian ini menggunakan pendekatan skor gabungan pada masing-masing dimensi pada analisis faktor yang pada pengujian sebelumnya sudah terbukti valid dan reliabel untuk seluruh item. Teknik ini dilakukan untuk menyederhanakan model sehingga membentuk pengukuran tingkat pertama. Karena secara empiris hasil pengujian pada tahap ujicoba maupun pada data penelitian sudah valid, maka skor-skor dimensi diperoleh dengan menggabungkan skor per dimensi sehingga membentuk variabel indikator pada model pengukuran level pertama (1st CFA). 
CENDEKIA, Vol. 12, No. 1, April 2018

p ISSN: 1978 2098; e ISSN: 2407 8557

Http://cendekia.pusatbahasa.or.id; Email: cendekiaoslo@gmail.com

Center of Language and Culture Studies, Surakarta, Indonesia

Herlambang, Erik \& Fuadi. 2018. Pengaruh Budaya Organisasi dan Komunikasi Interpersonal terhadap Kinerja Guru SMK Swasta di Kota Serang dengan Variabel Mediasi Komitmen Organisasi.

Cendekia, (2018), 12(1): 33 50. DOI: 10.30957/cendekia.v12i.435.

Tabel 1 Goodness of Fit Index (GOFI) Model 1st CFA

\begin{tabular}{|c|c|c|l|}
\hline GOFI & $\begin{array}{c}\text { Nilai } \\
\text { sebelum } \\
\text { perbaika } \\
\text { n }\end{array}$ & $\begin{array}{c}\text { Nilai Standar } \\
\text { untuk } \\
\text { Kecocokan } \\
\text { Baik }\end{array}$ & $\begin{array}{c}\text { Kesimpulan } \\
\text { Setelah } \\
\text { perbaikan }\end{array}$ \\
\hline p value $\chi^{2}$ & 0.125 & P value $>0.05$ & Kurang Baik \\
\hline RMSEA & 0.140 & RMSEA $\leq 0,08$ & Good fit \\
\hline NFI & 0.983 & NFI $\geq 0,90$ & Good fit \\
\hline NNFI & 0.961 & NNFI $\geq 0,90$ & Good fit \\
\hline CFI & 0.973 & CFI $\geq 0,90$ & Good fit \\
\hline IFI & 0.974 & IFI $\geq 0,90$ & Good fit \\
\hline GFI & 0.988 & GFI $\geq 0,90$ & Good fit \\
\hline AGFI & 0.977 & AGFI $\geq 0,90$ & Good fit \\
\hline
\end{tabular}

Sumber: data primer, diolah dengan LISREL versi 8.70 .

Berdasarkan delapan parameter kecocokan model di atas, mayoritas indeks kecocokan model sudah menunjukkan kecocokan yang baik (kecuali chi-square $p$ value dan NFI yang berada dalam marginal fit). Dengan demikian, dapat disimpulkan bahwa model pengukuran yang dipergunakan sudah fit dengan data sehingga tidak dilakukan perbaikan lebih lanjut.

\section{Pengujian Hipotesis}

Parameter uji hipotesis menggunakan perbandingan nilai $\mathrm{t}$, yaitu jika nilai $\mathrm{t}$ hitung > dari $\mathrm{t}$ table (1.96), maka $\mathrm{H}_{0}$ ditolak dan $\mathrm{H}_{1}$ diterima. Rangkuman hasil pengujian hipotesis selanjutnya dirangkum dalam Tabel berikut ini.

Tabel 2. Persamaan Struktural

\section{Structural Equations}

$\mathrm{KEP}=0.45 * \mathrm{BUD}+0.25 * \mathrm{KOM}$, Errorvar. $=0.463, \mathrm{R}^{2}=0.537$

$\begin{array}{lll}(0.0786) & (0.0818) & (0.108) \\ 4.241 & 3.044 & 6.424\end{array}$
$\mathrm{KIN}=0.467 * \mathrm{KOMIT}+0.444 * \mathrm{BUD}+0.324 * \mathrm{KOM}$, Errorvar. $=0.236, \mathrm{R}^{2}=0.764$
$\begin{array}{lll}(0.0898) & (0.0880) \quad(0.0829)\end{array}$
$4.088 \quad 4.020 \quad 2.711$
(0.110)
3.948

Sumber: data primer diolah (2017) 
CENDEKIA, Vol. 12, No. 1, April 2018

p ISSN: 1978 2098; e ISSN: 2407 8557

Http://cendekia.pusatbahasa.or.id; Email: cendekiaoslo@gmail.com

Center of Language and Culture Studies, Surakarta, Indonesia

Herlambang, Erik \& Fuadi. 2018. Pengaruh Budaya Organisasi dan Komunikasi

Interpersonal terhadap Kinerja Guru SMK Swasta di Kota Serang

dengan Variabel Mediasi Komitmen Organisasi.

Cendekia, (2018), 12(1): 33 50. DOI: 10.30957/cendekia.v12i.435.

Berdasarkan hasil structural tersebut, penjelasan mengenai hipotesis yang diajukan diuraikan sebagai berikut.

\section{Hipotesis Statistik ke-1:}

$\mathrm{H}_{0}: \gamma_{1}=0$ : Tidak ada pengaruh budaya organisasi terhadap komitmen organisasi

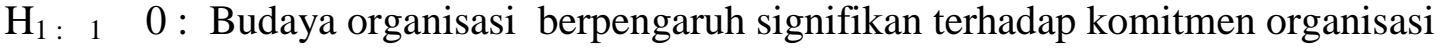

Pengaruh Budaya organisasi terhadap komitmen organisasi melalui nilai koefisien standard sebesar 0.613 dan t hitung sebesar 5.45. Nilai tersebut diperoleh memenuhi syarat untuk penerimaan $\mathrm{H}_{1}$ untuk hipotesis ke-1 yaitu nilai t hitung yang lebih besar dari 1,96. Dengan demikian dapat disimpulkan, dimensi-dimensi Budaya organisasi memiliki pengaruh positif dan signifikan terhadap komitmen organisasi. Dapat dinyatakan bahwa semakin baik budaya organisasi, maka akan berimplikasi pada semakin tingginya komitmen organisasi guru.

\section{Hipotesis Statistik ke-2:}

$\mathrm{H}_{0}: \gamma_{2}=0 \quad$ : Tidak ada pengaruh komunikasi interpersonal terhadap komitmen organisasi

$\mathrm{H}_{1}: \gamma_{2} \neq 0:$ Komunikasi interpersonal berpengaruh signifikan terhadap komitmen organisasi

Pengaruh komunikasi interpersonal terhadap komitmen organisasi melalui nilai koefisien standard sebesar 0.35 dan t hitung sebesar 3,14. Nilai tersebut diperoleh memenuhi syarat untuk penerimaan $\mathrm{H}_{1}$ untuk hipotesis ke-2 yaitu nilai t hitung yang lebih besar dari 1,96. Dengan demikian dapat disimpulkan, dimensi-dimensi komunikasi interpersonal memiliki pengaruh positif dan signifikan terhadap komitmen organisasi. Koefisien positif pada hubungan komunikasi interpersonal dengan komitmen organisasi ini menandakan bahwa semakin tingginya intensitas komunikasi interpersonal maka akan semakin tinggi pula komitmen organisasi.

\section{Hipotesis Statistik ke-3:}

$\mathrm{H}_{0}: \beta_{1}=0$ : Tidak ada pengaruh bersama-sama antara budaya organisasi dan komunikasi interpersonal terhadap komitmen organisasi

$\mathrm{H}_{1}: \beta_{1} \neq 0$ : budaya organisasi dan Komunikasi interpersonal secara bersama-sama berpengaruh signifikan terhadap komitmen organisasi

Persamaan yang diperoleh dari model komitmen organisasi melalui nilai standard estimate adalah sebagai berikut: $\mathrm{KOMIT}=0.513 * \mathrm{BUD}+0.349 * \mathrm{KOM}, \mathrm{R}^{2}=$ 0.407. Angka R square mengandung makna variasi komitmen organisasi mampu dijelaskan oleh budaya organisasi dan komunikasi interpersonal sebesar $40.7 \%$, dan sisanya 59.30\% dipengaruh faktor lain yang tidak diteliti dalam model. 
CENDEKIA, Vol. 12, No. 1, April 2018

p ISSN: 1978 2098; e ISSN: 2407 8557

Http://cendekia.pusatbahasa.or.id; Email: cendekiaoslo@gmail.com

Center of Language and Culture Studies, Surakarta, Indonesia

Herlambang, Erik \& Fuadi. 2018. Pengaruh Budaya Organisasi dan Komunikasi

Interpersonal terhadap Kinerja Guru SMK Swasta di Kota Serang

dengan Variabel Mediasi Komitmen Organisasi.

Cendekia, (2018), 12(1): 33 50. DOI: 10.30957/cendekia.v12i.435.

Karena estimasi pada model struktural ini menggunakan pendekatan regresi, maka evaluasi atas signifikansi model dihitung menggunakan uji $\mathrm{F}$

Di mana, $\mathrm{R}^{2}$ adalah koefisien determinasi, $\mathrm{n}$ adalah jumlah observasi, $\mathrm{m}$ adalah jumlah variabel bebas. Melalui perhitungan diperoleh nilai $\mathrm{F}$ hitung sebesar 52.15. Sedangkan nilai $\mathrm{F}$ tabel dengan jumlah variabel bebas 2 , dan $\mathrm{df}=\mathrm{n}-\mathrm{k}-1$ yaitu $\mathrm{n}$ adalah jumlah sampel, $\mathrm{k}$ adalah jumlah variabel bebas sehingga $\mathrm{df}=92-2-1=89$, sehingga diperoleh nilai $F$ tabel 3.03. Karena nilai $F$ hitung $>F$ tabel $(52.15>3.03)$, maka model simultan $\mathrm{H}_{1}$ untuk hipotesis ke-3 ini diterima.

Melalui perbandingan nilai standardized coefficient diketahui bahwa dari dua eksogen yang digunakan, budaya organisasi merupakan variabel yang dominan menjelaskan terhadap komitmen organisasi dengan standardized coefficient sebesar 0.51 , kemudian komunikasi interpersonal dengan koefisien standar sebesar 0.35.

\section{Hipotesis Statistik ke-4:}

$\mathrm{H}_{0}: \gamma_{3}=0$ : Tidak ada pengaruh budaya organisasi terhadap kinerja guru

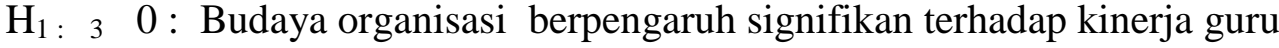
Hasil perhitungan:

Koefisien jalur budaya organisasi terhadap kinerja menunjukkan nilai coefisien standard sebesar 0.454 dan t hitung sebesar 4.120. Nilai tersebut sudah memenuhi syarat untuk penerimaan $\mathrm{H}_{1}$ untuk hipotesis ke-4 yaitu nilai t hitung yang lebih besar dari 1,96. Dengan demikian dapat disimpulkan, dimensi-dimensi Budaya organisasi terbukti berpengaruh signifikan terhadap kinerja guru. Dapat dinyatakan bahwa semakin baik budaya organisasi maka akan semakin baik pula kinerja guru Tersebut, dan sebaliknya, semakin rendah budaya organisasi maka akan berimplikasi pada rendahnya kinerja guru.

\section{Hipotesis Statistik ke-5:}

$\mathrm{H}_{0}: \gamma_{4}=0$ : Tidak ada pengaruh Komunikasi interpersonal terhadap Kinerja guru

$\mathrm{H}_{1}: \gamma_{4} \neq 0$ : Komunikasi interpersonal berpengaruh signifikan terhadap Kinerja guru

Hasil perhitungan:

Koefisien jalur komunikasi interpersonal terhadap kinerja menunjukkan nilai koefisien standard sebesar 0.325 dan t hitung sebesar 2.811. Nilai tersebut sudah memenuhi syarat untuk penerimaan $\mathrm{H}_{1}$ untuk hipotesisi ke-5 yaitu nilai t hitung yang lebih besar dari 1,96. Dengandemikian dapat disimpulkan, dimensi-dimensi komunikasi interpersonal terbukti berpengaruh signifikan terhadap kinerja guru.

\section{Hipotesis statistic ke-6:}

$\mathrm{H}_{0}: \beta_{1}=0$ : Tidak ada pengaruh komitmen organisasi terhadap kinerja guru

$\mathrm{H}_{1}: \beta_{1} \neq 0$ : komitmen organisasi berpengaruh signifikan terhadap kesejahteaan guru 
CENDEKIA, Vol. 12, No. 1, April 2018

p ISSN: 1978 2098; e ISSN: 2407 8557

Http://cendekia.pusatbahasa.or.id; Email: cendekiaoslo@gmail.com

Center of Language and Culture Studies, Surakarta, Indonesia

Herlambang, Erik \& Fuadi. 2018. Pengaruh Budaya Organisasi dan Komunikasi

Interpersonal terhadap Kinerja Guru SMK Swasta di Kota Serang

dengan Variabel Mediasi Komitmen Organisasi.

Cendekia, (2018), 12(1): 33 50. DOI: 10.30957/cendekia.v12i.435.

Koefisien jalur komitmen organisasi terhadap kinerja guru menunjukkan nilai koefisien standard sebesar 0.467 dan t hitung sebesar 4.188. Nilai tersebut diperoleh memenuhi syarat untuk penerimaan $\mathrm{H} 1$ untuk hipotesis ke-6 yaitu nilai t hitung yang lebih besar dari 1,96. Dengan demikian dapat disimpulkan, dimensi-dimensi komitmen organisasi memiliki pengaruh positif dan signifikan terhadap kinerja guru. Dengan kata lain, semakin tinggi komitmen organisasi maka akan berimplikasi pada tingginya kinerja guru, dan sebaliknya, rendahnya komitmen organisasi akan menurunkan kinerja guru.

Persamaan yang diperoleh dari model kinerja melalui nilai standard estimate adalah sebagai berikut: KIN $=0.467 * \mathrm{KOMIT}+0.454 * \mathrm{BUD}+0.325 * \mathrm{KOM}$, Errorvar.= $0.536, \mathrm{R}^{2}=0.464$. Angka $R$ square mengandung makna variasi kinerja mampu dijelaskan oleh Budaya organisasi, Pengembangan karir, dan Komitmen organisasi sebesar $56.50 \%$, dan sisanya $43.50 \%$ dipengaruh faktor lain yang tidak diteliti dalam model. Sumbangan ketiga variabel di atas yang hanya 56,50\% dapat dikatakan relatif kecil, sehingga kinerja diperngahui oleh faktor lain antara lain dimaksud antara lain, pembinaan terhadap Guru, enterpreneurship, kemapanan bekerja, lama mengajar, dan lain-lain. Karena estimasi pada model struktural ini menggunakan pendekatan regresi, maka evaluasi atas signifikansi model dihitung menggunakan uji $\mathrm{F}$.

Di mana, $\mathrm{R}^{2}$ adalah koefisien determinasi, $\mathrm{n}$ adalah jumlah observasi, $\mathrm{m}$ adalah jumlah variabel bebas. Melalui perhitungan diperoleh nilai $\mathrm{F}$ hitung sebesar 101.86 Sedangkan nilai $F$ tabel dengan jumlah variabel bebas 4 , dan $\mathrm{df}=\mathrm{n}-\mathrm{k}-1$ yaitu $\mathrm{n}$ adalah jumlah sampel, $\mathrm{k}$ adalah jumlah variabel bebas sehingga $\mathrm{df}=92-3-1=88$, sehingga diperoleh nilai $\mathrm{F}$ tabel 2.64. Karena nilai $\mathrm{F}$ hitung $>\mathrm{F}$ tabel $(101.86>2.64)$, maka model simultan ini diterima.

Variabel yang lebih dominan menjelaskan kinerja yaitu variabel komitmen organisasi dengan koefisien standar sebesar 0.467, disusul variabel budaya organisasi dengan koefisien standar sebesar 0.454, kemudian terakhir komunikasi interpersonal dengan koefisien standar sebesar 0.325 .

Secara keseluruhan, penelitian ini berhasil membuktikan seluruh hipotesis yang diajukan. Rangkungan hasil pengujian secara keseluruhan dapat dilihat pada tabel berikut. 
CENDEKIA, Vol. 12, No. 1, April 2018

p ISSN: 1978 2098; e ISSN: 2407 8557

Http://cendekia.pusatbahasa.or.id; Email: cendekiaoslo@gmail.com

Center of Language and Culture Studies, Surakarta, Indonesia

Herlambang, Erik \& Fuadi. 2018. Pengaruh Budaya Organisasi dan Komunikasi

Interpersonal terhadap Kinerja Guru SMK Swasta di Kota Serang

dengan Variabel Mediasi Komitmen Organisasi.

Cendekia, (2018), 12(1): 33 50. DOI: 10.30957/cendekia.v12i.435.

Tabel 3. Rangkuman Pengujian Hipotesis

\begin{tabular}{|c|l|c|c|c|l|}
\hline No & \multicolumn{1}{|c|}{ Statement } & $\begin{array}{c}\text { Koefisien } \\
\text { unstandard }\end{array}$ & $\begin{array}{c}\text { Koefisien } \\
\text { standardized }\end{array}$ & $\begin{array}{c}\mathrm{t} \\
\text { hitung }\end{array}$ & \multicolumn{1}{|c|}{ Kesimpulan } \\
\hline 1 & BUD $\rightarrow$ KOMIT & 0.513 & 0.513 & 5.351 & $\begin{array}{l}\text { H0 ditolak, H1 } \\
\text { diterima } \\
\text { (Signifikan) }\end{array}$ \\
\hline 2 & KOM $\rightarrow$ KOMIT & 0.349 & 0.349 & 3.144 & $\begin{array}{l}\text { H0 ditolak, H1 } \\
\text { diterima } \\
\text { (Signifikan) }\end{array}$ \\
\hline 3 & BUD + KOM $\rightarrow$ KOMIT & $\mathrm{R}^{2}=0.407$ & - & $\begin{array}{l}\text { F hitung } \\
=52.15\end{array}$ & $\begin{array}{l}\text { H0 ditolak, H1 } \\
\text { diterima } \\
\text { (Signifikan) }\end{array}$ \\
\hline 4 & BUD $\rightarrow$ KIN & 0.454 & 0.454 & 4.120 & $\begin{array}{l}\text { H0 ditolak, H1 } \\
\text { diterima } \\
\text { (Signifikan) }\end{array}$ \\
\hline 5 & KOM $\rightarrow$ KIN & 0.325 & 0.325 & 2.811 & $\begin{array}{l}\text { H0 ditolak, H1 } \\
\text { diterima } \\
\text { (Signifikan) }\end{array}$ \\
\hline 6 & KOMIT $\rightarrow$ KIN & 0.467 & 0.467 & 4.188 & $\begin{array}{l}\text { H0 ditolak, H1 } \\
\text { diterima } \\
\text { (Signifikan) }\end{array}$ \\
\hline 7 & $\begin{array}{l}\text { BUD +KOM+ KOMIT } \rightarrow \\
\text { KIN }\end{array}$ & $\mathrm{R}^{2}=0.664$ & & F hitung \\
$=101.86$ & $\begin{array}{l}\text { H0 ditolak, H1 } \\
\text { diterima } \\
\text { (Signifikan) }\end{array}$ \\
\hline Sur & & & & & \\
\hline
\end{tabular}

Sumber : output LISREL, diolah

Apabila dibedakan antara pengaruh antara budaya organisasi terhadap kinerja secara langsung dibandingkan dengan pengaruh budaya organisasi terhadap kinerja melalui variabel komitmen organisasi, maka dapat dihitung sebagai berikut.

Pengaruh antara budaya organisasi terhadap kinerja secara langsung yaitu sebesar $0,45 \times 0,45=0.20$. Sementara itu, pengaruh budaya organisasi terhadap kinerja melalui variabel komitmen organisasi yaitu sebesar $0,51 \times 0,47=0,24$. Dengan demikian, variabel budaya organisasi mempunyai pengaruh tidak langsung melalui variabel intervening komitmen organisasi yang lebih besar dibandingkan pengaruh secara langsung.

Apabila dibedakan antara pengaruh antara komunikasi interpersonal terhadap kinerja secara langsung dibandingkan dengan pengaruh komunikasi interpersonal terhadap kinerja melalui variabel komitmen organisasi, maka dapat dihitung sebagai berikut. 
CENDEKIA, Vol. 12, No. 1, April 2018

p ISSN: 1978 2098; e ISSN: 2407 8557

Http://cendekia.pusatbahasa.or.id; Email: cendekiaoslo@gmail.com

Center of Language and Culture Studies, Surakarta, Indonesia

Herlambang, Erik \& Fuadi. 2018. Pengaruh Budaya Organisasi dan Komunikasi

Interpersonal terhadap Kinerja Guru SMK Swasta di Kota Serang

dengan Variabel Mediasi Komitmen Organisasi.

Cendekia, (2018), 12(1): 33 50. DOI: 10.30957/cendekia.v12i.435.

Pengaruh antara komunikasi interpersonal terhadap kinerja secara langsung yaitu sebesar $0,32 \times 0,32=1.04$. Sementara itu, pengaruh komunikasi interpersonal terhadap kinerja melalui variabel komitmen organisasi yaitu sebesar $0,35 \times 0,47=$ 1,64. Dengan demikian, variabel komunikasi interpersonal mempunyai pengaruh tidak langsung melalui variabel intervening komitmen organisasi yang lebih besar dibandingkan pengaruh secara langsung.

\section{BAHASAN}

Sebagaimana hasil penelitian di atas diketahui: Pertama, bahwa budaya organisasi berpengaruh secara signifikan terhadap komitmen organisasi. Hasil penelitian ini mendukung temuan Bouffard, dkk (2003) yang menemukan adanya pengaruh budaya organisasi secara signifikan terhadap komitmen karyawan terhadap organisasi..

Hasil temuan ini sejalan dengan penelitian yang dilakukan oleh Darlius (2009), yang menyimpulkan bahwa budaya organisasi berpengaruh secara positif dan signifikan terhadap komitmen organisasi karyawan Kantor Pelayanan Pajak Pratama Di Lingkungan Kantor Wilayah Jakarta Barat. Pengaruh variabel budaya organisasi lebih besar dibandingkan pengaruh kepemimpinan terhadap komitmen organisasi.

Dengan demikian dapat pahami bahwa pengaruh antara budaya organisasi dan komitmen karyawan terhadap organisasi merupakan sebuah hubungan yang bersifat positif, artinya semakin baik budaya organisasi yang dibangun oleh sekolah maka akan semakin tinggi komitmen guru-guru terhadap organisasi

Kedua, hasil penelitian ini menunjukkan bahwa komunikasi interpersonal berpengaruh terhadap komitmen organisasi. Hal ini sesuai dengan temuan Cherian dan Jacob (2013) yang menemukan komunikasi interpersonal memiliki pengaruh terhadap komitmen organisasi dan kinerja. Penelitian lainnya oleh Mojavezi dan Tamiz (2012) juga berhasil menyimpulkan bahwa komunikasi interpersonal memiliki efek yang positif dan signifikan pada komitmen organisasi.

Hasil penelitian ini sesuai dengan temuan Lunenburg (2011) yang menyimpulkan bahwa komunikasi interpersonal mampu meningkatkan komitmen organisasi. Pekerja yang mempunyai komunikasi interpersonal yang tinggi akan sukses dalam melaksanakan kerja karena ia juga akan mempunyai komitmen organisasi yang tinggi.

Dengan demikian dapat dimengerti, bagaimana hubungan antara komunikasi interpersonal dan komitmen organisasi merupakan sebuah hubungan yang bersifat positif, artinya semakin baik komunikasi interpersonal guru maka akan semakin tinggi komitmen mereka terhadap organisasi

Ketiga, hasil penelitian ini juga menemukan bahwa budaya organisasi dan komunikasi interpersonal secara bersama-sama dapat berpengaruh terhadap komitmen guru terhadap organisasi. Dalam arti bahwa budaya organisasi yang dikembangkan oleh sekolah tempat guru mengajar dan komunikasi interpersonal 
CENDEKIA, Vol. 12, No. 1, April 2018

p ISSN: 1978 2098; e ISSN: 2407 8557

Http://cendekia.pusatbahasa.or.id; Email: cendekiaoslo@gmail.com

Center of Language and Culture Studies, Surakarta, Indonesia

Herlambang, Erik \& Fuadi. 2018. Pengaruh Budaya Organisasi dan Komunikasi

Interpersonal terhadap Kinerja Guru SMK Swasta di Kota Serang

dengan Variabel Mediasi Komitmen Organisasi.

Cendekia, (2018), 12(1): 33 50. DOI: 10.30957/cendekia.v12i.435.

antara guru dan guru secara bersama-sama akan dapat meningkatkan komitmen para guru terhadap organisasi sekolah.

Hasil penelitian ini sesuai dengan temuan Pitoewas (2013) yang menyimpulkan bahwa terdapat pengaruh positif dan signifikan secara bersama-sama antara budaya organisasi dan komunikasi interpersonal terhadap komitmen organisasi.

Hasil penelitian ini juga menguatkan hasil penelitian Natalia Damayanti, (2008) yang menyimpulkan bahwa budaya organisasi dan Komunikasi interpersonal berpengaruh secara bersama-sama terhadap komitmen organisasi dengan $\mathrm{R}=0,783$ dengan $\mathrm{F}=59,039$ dan $\mathrm{p}<0,01)$.

Keempat, hasil penelitian menunjukkan bahwa budaya organisasi berpengaruh terhadap kinerja. Dengan kata lain semakin baik budaya organisasi yang dikembangkan oleh sekolah maka akan semakin baik juga kinerja guru. Hal ini sesuai dengan temuan Abraido-Lanza (2007) dalam penelitiannya memberikan kesimpulan bahwa budaya organisasi memainkan peranan penting dalam meningkatkan kinerja (well being). Dalam riset yang lebih baru, Saaranen, dkk (2012) yang meneliti di lingkungan pendidikan menyimpulkan bahwa pentingnya memelihara budaya organisasi dalam meningkatkan kinerja karyawan.

Hasil penelitian ini sesuai dengan temuan Ketut Sudarma (2011) yang menyimpulkan bahwa budaya organisasi berpengaruh secara signifikan terhadap kinerja pekerja dengan sumbangan sebesar 47,6\%.

Kelima, hasil penelitian menunjukkan bahwa komunikasi interpersonal berpengaruh terhadap kinerja. Dalam arti semakin baik komunikasi interpersonal seseorang semakin baik juga kinerja mereka. Sebaliknya, semakin buruk komunikasi interpersonal yang dibangun oleh seseorang, semakin rendah pula kinerja orang tersebut.

Hal ini sesuai dengan temuan Mamta dan Sharma (2013), menyebutkan bahwa ada korelasi positif yang signifikan antara komunikasi interpersonal semakin tinggi pula kinerja yang disuguhkan karyawan untuk organisasinya. Hasil penelitian ini juga mendukung temuan Upadhyay dan Singh (2011) yang menyimpulkan bahwa komunikasi interpersonal adalah prediktor kuat dari kinerja, artinya, kinerja seseorang sangat dipengaruhi oleh komunikasi interpersonal yang dilakukan oleh orang tersebut. Pezent (2011) mengamati bahwa komunikasi interpersonal mungkin memainkan peran penting dalam mempertahankan kinerja karyawan.

Hasil penelitian ini juga tidak berbeda jauh dengan hasil temuan Lunenburg (2011) yang menyimpulkan bahwa komunikasi interpersonal yang tinggi akan mampu penghasilan produk yang lebih baik.

Keenam, hasil penelitian menunjukkan bahwa komitmen organisasi berpengaruh terhadap kinerja guru. Semakin baik komitmen guru pada sekolah yang ditempati, maka semakin baik pula kinerja guru tersebut.

Hal ini sesuai dengan temuan Suroyo, dkk, (2013) yang menyimpulkan bahwa komitmen organisasi berpengaruh yang signifikan terhadap kinerja dengan $\mathrm{r}$ sebesar 
CENDEKIA, Vol. 12, No. 1, April 2018

p ISSN: 1978 2098; e ISSN: 2407 8557

Http://cendekia.pusatbahasa.or.id; Email: cendekiaoslo@gmail.com

Center of Language and Culture Studies, Surakarta, Indonesia

Herlambang, Erik \& Fuadi. 2018. Pengaruh Budaya Organisasi dan Komunikasi

Interpersonal terhadap Kinerja Guru SMK Swasta di Kota Serang

dengan Variabel Mediasi Komitmen Organisasi.

Cendekia, (2018), 12(1): 33 50. DOI: 10.30957/cendekia.v12i.435.

0,513. Dengan hasil ini diketahui bahwa komitmen organisasi sangat mempengaruhi tingkat kinerja dan sebaliknya.

Selanjutnya, penelitian ini sesuai dengan hasil penelitian yang dilakukan Emmy Endrawati dan Novita Sulistyowati, (2010) yang menyimpulkan bahwa komitmen organisasi memberikan sumbangan terhadap kinerja pegawai sebesar 91,2\%.

Ketujuh, hasil penelitian menunjukkan bahwa budaya organisasi, komunikasi interpersonal, dan komitmen organisasi berpengaruh secara bersama-sama terhadap kinerja guru. Hal ini sesuai dengan temuan Rohani (2012) yang menyimpulkan bahwa terdapat pengaruh yang signinfikan antara budaya organisasi, komunikasi interpersonal, dan komitmen organisasi berpengaruh secara bersama-sama terhadap kinerja karyawan.

\section{SIMPULAN}

Sebagaimana hasil penelitian di atas dapat disimpulkan sebagai berikut.

Pertama, budaya organisasi berpengaruh secara positif dan signifikan terhadap komitmen guru SMK Swasta di Kota Serang.

Kedua, komunikasi interpersonal berpengaruh secara positif dan signifikan terhadap komitmen guru SMK Swasta di Kota Serang.

Ketiga, budaya organisasi dan komunikasi interpersonal secara bersama-sama berpengaruh secara positif dan signifikan terhadap komitmen guru terhadap organisasi SMK Swasta di Kota Serang.

Keempat, budaya organisasi berpengaruh secara positif dan signifikan terhadap kinerja SMK Swasta di Kota Serang.

Kelima, komunikasi interpersonal berpengaruh secara positif dan signifikan terhadap kinerja SMK Swasta di Kota Serang.

Keenam, komitmen organisasi berpengaruh secara positif dan signifikan terhadap kinerja guru SMK Swasta di Kota Serang.

Ketujuh, budaya organisasi, komunikasi interpersonal, dan komitmen organisasi berpengaruh secara positif dan signifikan secara bersama-sama terhadap kinerja guru SMK Swasta di Kota Serang

\section{REFERENSI}

Bouffard, Therese; Marcoux, Marie-France; Vezeau, Carole; Bordeleau, Luce. 2003. Changes in Self-Perceptions of Competence and Intrinsic Motivation among Elementary School Children. British Journal of Educational Psychology 73(2): 171-182.

Cherian, Jacob; Jacob, Jolly. 2013. Impact of Self Efficacy on Motivation and Performance of Employees. International Journal of Business and Management 8.14 (2013): 80-88.

Darlius. 2009. Pengaruh Kepemimpinan dan Kompetensi Kerja terhadap Motivasi Kerja: Studi Kasus pada Kantor Pelayanan Pajak Pratama di Lingkungan Kantor Wilayah Jakarta Barat, Disertasi, Jakarta: PPs UPI Y.A.I 
CENDEKIA, Vol. 12, No. 1, April 2018

p ISSN: 1978 2098; e ISSN: 2407 8557

Http://cendekia.pusatbahasa.or.id; Email: cendekiaoslo@gmail.com

Center of Language and Culture Studies, Surakarta, Indonesia

Herlambang, Erik \& Fuadi. 2018. Pengaruh Budaya Organisasi dan Komunikasi Interpersonal terhadap Kinerja Guru SMK Swasta di Kota Serang dengan Variabel Mediasi Komitmen Organisasi. Cendekia, (2018), 12(1): 33 50. DOI: 10.30957/cendekia.v12i.435.

Devito, Joseph A. 1997. Komunikasi Antarmanusia, Jakarta: Professional Books Emmy Endrawati dan Novita Sulistyowati, 2010, The Antecedents of Motivation and Its Impact on Perceived Welfare of Credit Union Member, The First International Credit Union Conference on Social Micro finance and Community Development, BKCU Kalimantan-Gunadarma University

Ketut Sudarma. 2011. Analisis Kesejahteraan Berbasis Kinerja Melalui Competency dan Organizational Citizenship Behavior (OCB) pada Tenaga Administrasi: Studi Kasus pada Universitas Negeri Semarang (UNNES), Dinamika Sosial Ekonomi, 7(1):35--46

Lumbanraya, Prihatin, 2009, Pengaruh Karaketeristik Individu, Gaya Kepemimpinan, Budaya Organisasi terhadap Kepuasan Kerja dan Komitmen Organisasi (Studi pada Pemerintah Daerah di Provinsi Sumateria Utara), Jurnal Aplikasi Manajemen, 7(2):450-468.

Lunenburg, Fred C.. 2011. Self-Efficacy in the Work Place: Implications for Motivation and Performance. International Journal of Management, Business, and Administration. 14(1):1-12.

Lunenburg, Fred C.. 2011. Self-Efficacy in the Work Place: Implications for Motivation and Performance. International Journal of Management, Business, and Administration. 14(1):856-868.

Mamta, Sharma, dan Nov Rattan. 2013. Resilience and Self-efficacy as Correlates of Well-being among the Elderly Persons. Journal of the Indian Academy of Applied Psychology, 39(2): 281-288.

Mathis, R.1 \& J.H. Jackson, (2001) Manajemen Sumber Daya Manusia. Buku I. Penerjemah Benyamin Molan. Jakarta: PT Salemba Emban Patria

Natalia Damayanti. 2008. Pengaruh Kompetensi Guru,Ketakutan Akan Kegagalan, Dan Self Efficacy Terhadap Motivasi Belajar Matematika. Hasil Penelitian, Unika Soegijapranata. Diunduh tanggal 1 Desember 2014 dari http://eprints.unika.ac.id/1663/

Pezent, GD. 2011. Exploring the Role of Positive Psychology Constructs as Protective Factors Against the Impact of Negative Environmental Variables on the Subjective Well-being of Older Adults. Doctoral dissertation. Texas A \& M University, Texas.

Pitoewas. 2013. Pengaruh antara Kompetensi dan Kepercayaan terhadap Motivasi Kerja Guru SMA di SMA YP Unila, Hasil penelitian, Bandar Lampung: FKIP Unila

Rivai, Veitzal dan Fawzi Sagala (2004) Performance Appraisal Ed ke-1. Jakarta: PT Raja Gravindo Persada.

Rohani. 2012. Pengaruh antara Kompetensi, Kepercayaan Diri dan Motivasi terhadap Kesejahteraan Karyawan PT Indosat region Jawa Timur, Disertasi, Malang: Universitas Brawijaya 
CENDEKIA, Vol. 12, No. 1, April 2018

p ISSN: 1978 2098; e ISSN: 2407 8557

Http://cendekia.pusatbahasa.or.id; Email: cendekiaoslo@gmail.com

Center of Language and Culture Studies, Surakarta, Indonesia

Herlambang, Erik \& Fuadi. 2018. Pengaruh Budaya Organisasi dan Komunikasi Interpersonal terhadap Kinerja Guru SMK Swasta di Kota Serang dengan Variabel Mediasi Komitmen Organisasi. Cendekia, (2018), 12(1): 33 50. DOI: 10.30957/cendekia.v12i.435.

Saaranen, Terhi; et al. 2012. The Occupational Well-Being of School Staff and Maintenance of their Ability to Work in Finland and Estonia - Focus on the School Community and Professional Competence. Health Education, 112(3): 236-255.

Sagala, Syaiful (2007). Manajemen Stategik Dalam Peningkatan Mutu Pendidikan. Bandung Alfbeta.

Sagala, Syaiful. (2007). Desain Organisasi Pendidikan dalam Implementasi Kebijakan Otonomi Daerah. Jakarta: Uhamka Press.

Suroyo, dkk. 2013. The Effect of Regent Leadership Style on Motivation, Village Prosperity and Headman Performance in Increasing Society Social Welfare (A Study in Headman Office at Bekasi Regency, West Java, Indonesia), IOSR Journal of Business and Management (IOSR-JBM), 9(6): 48-52 diunduh tanggal 18 Agustus 2013 dari http:/www.iosrjournals.org 
CENDEKIA, Vol. 12, No. 1, April 2018

p ISSN: 1978 2098; e ISSN: 2407 8557

Http://cendekia.pusatbahasa.or.id; Email: cendekiaoslo@gmail.com

Center of Language and Culture Studies, Surakarta, Indonesia

Herlambang, Erik \& Fuadi. 2018. Pengaruh Budaya Organisasi dan Komunikasi

Interpersonal terhadap Kinerja Guru SMK Swasta di Kota Serang

dengan Variabel Mediasi Komitmen Organisasi.

Cendekia, (2018), 12(1): 33 50. DOI: 10.30957/cendekia.v12i.435. 